\author{
SVEN DUPRÉ
}

UNIVERSITEIT UTRECHT

UNIVERSITEIT VAN AMSTERDAM

\title{
Las tecnologías visuales en movimiento
}

\section{La materialidad de las tecnologias visuales ${ }^{\mathrm{I}}$}

\begin{abstract}
$\mathrm{E}$ stas páginas abogan por la importancia de reconocer la materialidad de los instrumentos de visión y de las tecnologías visuales. ${ }^{2}$ La materialidad de los instrumentos de visión es precisamente lo que tiende a omitirse en la obra fundacional de Jonathan Crary, Techniques of the Observer. Convencido de que una historia de la visión o de la percepción "depende mucho más que de una simple enumeración de cambios o desplazamientos de las prácticas representacionales", este autor enfocó la problemática en el observador. Así, sostuvo que "la visión y sus efectos son siempre inseparables de las posibilidades de un sujeto observador, que es a la vez un producto histórico y el lugar de ciertas prácticas, técnicas, instituciones, y procedimientos de subjetivación”. ${ }^{3}$
\end{abstract}

I. La edición y traducción del artículo del inglés al español estuvo a cargo de Nydia Pineda de Ávila, de la University of California, San Diego.

2. Este artículo deriva de la conferencia magistral "Visual Technologies on the Move" presentada el I de febrero de 2019 en el taller internacional e interdisciplinario Diálogos sobre imágenes astronómicas en América. Siglos XVI-XIX, una colaboración entre el Instituto de Investigaciones Estéticas, el Programa Arte-Ciencia y Tecnologías por medio del Instituto de Astronomía (UNAM), y la John Carter Brown Library en Brown University.

3. Jonathan Crary, Las técnicas del observador. Visión y modernidad en el siglo XIX (Murcia: CENDEAC, 2008), $2 \mathrm{I}$. 


\section{DOI: https://doi.org/10.22201/iie.18703062e.2021.118.2740}

I4

SVEN DUPRÉ

La tesis básica de Crary es que a principios del siglo XIX surgió un nuevo tipo de observador. Entre i81o y I820, el autor localizó en el régimen escópico una ruptura entre un modelo geométrico de visión (donde la visión es esencialmente pasiva, independiente del sujeto, y basada en una distinción radical entre interior y exterior) y un modelo fisiológico (en el que la visión se vuelve subjetiva y el producto de la experiencia visual se localiza en el cuerpo del observador). Crary desarrolla esta tesis al contrastar dos instrumentos: la cámara oscura y el estereoscopio, los cuales, respectivamente, consideraba paradigmáticos de sus dos modelos de visión. Así, escribió:

Los dispositivos ópticos en cuestión, de manera significativa, son puntos de intersección en los que los discursos filosóficos, científicos y estéticos se solapan con técnicas mecánicas, requerimientos institucionales y fuerzas socioeconómicas. Cada uno de ellos puede entenderse no simplemente en tanto objeto material, o como parte de una historia de la tecnología, sino a través del modo en que se inserta en un agenciamiento mucho más amplio de acontecimientos y poderes. ${ }^{4}$

De esta manera, Crary procuró alejarse de toda suposición de que los artistas usaban instrumentos ópticos para lograr imágenes fotográficamente realistas; entendido tácito que, valga decirlo, se desarrolló en la obra ampliamente conocida Secret Knowledge de David Hockney. ${ }^{5}$ Crary sostuvo que:

Muchos análisis de la cámara oscura, en concreto los relativos al siglo xviII, propenden a considerar su uso exclusivamente como instrumento para copiar, y como un auxiliar en la creación de pinturas por parte de los artistas. A menudo se presume que estos artistas trabajaban con un sucedáneo de lo que querían realmente, y que aparecería pronto, a saber: la cámara fotográfica. ${ }^{\circ}$

Esta deconstrucción de la historia de la cámara oscura como preludio de la cámara fotográfica es lo que se gana en el replanteamiento de la historia del observador y de las técnicas de observación que propone Crary. Sin embargo,

4. Crary, Las técnicas del observador, 24.

5. David Hockney, Secret Knowledge: Rediscovering the Lost Techniques of the Old Masters (Londres: Thames \& Hudson, 200I); Sven Dupré, “Optics, Instruments and Painting, I4201720: Reflections on the Hockney-Falco Thesis", Early Science and Medicine Io, núm. 2 (2005): I25-339.

6. Crary, Las técnicas del observador, 55 . 
esta versión también cae en la trampa de declarar que la cámara oscura es paradigmática de un régimen escópico, con todos los problemas subsecuentes que fueron diagnosticados en la historia de medios de Bernhard Siegert: este abordaje coloca la historicidad y la pluralidad de las relaciones humano-tecnología en una caja negra. ${ }^{7}$ Tanto la repentina transposición de la visión dentro del cuerpo a principios del siglo XIX descrita por Crary, como la distinción tajante entre un régimen escópico geométrico y uno fisiológico en la historia de la observación, han sido criticadas repetida y justificadamente por, entre otros, Erna Fiorentini en su trabajo sobre la cámara lúcida. ${ }^{8}$ Yo voy a plantear que el observador de la cámara oscura no es un ente pasivo sino un sujeto que experimenta y juega de forma constante con el diseño del dispositivo, y que en la modernidad temprana (o sea, antes del siglo xix) la observación con este instrumento dependía de un involucramiento y entrecruzamiento corpóreo $^{9}$ más que de una división estricta entre el sujeto y el objeto, dos elementos que Crary subestimaba al desmaterializar la cámara oscura. ${ }^{10}$ La palabra clave en este acercamiento es movilidad, que actúa sobre tres niveles: I) la movilidad y la animación de imágenes; 2) la materialidad movible de los instrumentos, y 3) la movilidad en términos de la portabilidad de las tecnologías visuales hacia diferentes sitios y continentes.

\section{La cámara oscura: ¿portabilidad?}

Vale la pena discutir dos momentos en la historia de la cámara oscura. El primero conecta la cámara oscura con la observación astronómica. En la óptica medieval el llamado problema de las imágenes estenopeicas era ampliamente discutido, en

7. Bernhard Siegert, "Kulturtechnik', en Einführung in die Kulturwissenschaft, Harun Maye y Leander Scholz, eds. (Múnich: Wilhelm Fink Verlag, 20II), 95-II8.

8. Erna Fiorentini, "Subjective Objective. The Camera Lucida and Protomodern Observers”, Bildwelten des Wissens: Kunsthistorisches Jahrbuch für Bildkritik, núm. 2 (2004): 58-66.

9. N. de la traductora. A partir del diálogo con el autor, se ha traducido el concepto de embodiment como "involucramiento y entrecruzamiento corpóreo", para mostrar la influencia de Merleau Ponty en este abordaje.

Io. Crary sólo escribe sobre la idea de la cámara oscura. En este enfoque, la cámara oscura es siempre una máquina creadora de imágenes con un observador humano pasivo. Sobre la perspectiva y el cuerpo, especialmente en relación con imágenes anamórficas, véase también: Lyle Massey, Picturing Space, Displacing Bodies: Anamorphosis in Early Modern Theories of Perspective (University Park, Pensilvania: The Pennsylvania State University Press, 2007). 


\section{DOI: https://doi.org/10.22201/iie.18703062e.2021.118.2740}

término teóricos, en el contexto de la propagación de la luz. Roger Bacon, John Pecham y Witelo, los autores más importantes en la disciplina óptica, no lograron explicar por qué la luz, al pasar a cierta distancia por aperturas de formas cualesquiera, reproducía de manera consistente el contorno de la fuente lumínica en vez de la forma de la apertura. Es relevante señalar que antes de Johannes Kepler los autores de textos ópticos no entendían este proceso en relación con la creación de imágenes. Tampoco concebían dicha colocación de la apertura como una cámara oscura. Para ellos, se trataba tan sólo de la propagación de la luz. ${ }^{\text {II }}$ En segundo lugar, prácticamente desde el siglo XIII, la cámara oscura se usaba con fines astronómicos. En I292, el astrónomo, matemático y exégeta bíblico Levi ben Gerson y William de Saint-Cloud usaron la cámara oscura para proyectar una imagen del sol en una pantalla para observar eclipses solares. ${ }^{12}$ En este contexto, el uso de la cámara oscura exigía buscar un método correcto para medir el diámetro solar aparente. A mediados del siglo XVI, este uso de la cámara oscura parece haber entrado en las prácticas comunes de astrónomos como Erasmus Reinhold, Gemma Frisius y Tycho Brahe. ${ }^{13}$ Por un camino con seguridad independiente de los trabajos de Levi ben Gerson, en el siglo XvII Kepler halló una solución para medir el diámetro aparente del Sol sustrayendo el tamaño de la apertura del tamaño aparente de la luminaria proyectada en la pantalla de la cámara oscura. ${ }^{14}$ Por último, las líneas meridianas propiciaron otro contexto astronómico para el uso de la cámara oscura: una iglesia entera se convertía en una cámara oscura gigantesca para estudiar cómo la imagen del sol proyectada por una pequeña apertura atravesaba la línea meridiana trazada sobre el piso. ${ }^{\text {I5 }}$

II. En la óptica medieval no existe un interés por la inversión de la imagen. Para la distinción entre la disciplina óptica como el estudio de la luz y el estudio de la visión, véase: A. Mark Smith, From Sight to Light: The Passage from Ancient to Modern Optics (Chicago: University of Chicago Press, 2015).

I2. Bernard R. Goldstein, "The Physical Astronomy of Levi Ben Gerson”, Perspectives on Science, núm. 5 (1997): I-30, especialmente, 7-9; José Luis Mancha, "Astronomical Use of Pinhole Images in William of Saint-Cloud's Almanach Planetarum (I292)”, Archive for History of Exact Sciences, núm. 43 (1992): 275-298.

13. Stephen Mory Straker, "Kepler's Optics: A Study in the Development of Seventeenth Century Natural Philosophy", tesis de doctorado (Indiana: Indiana University, 197I), 304-36I.

I4. Stephen Mory Straker, "Kepler, Tycho, and the 'Optical Part of Astronomy': The Genesis of Kepler's Theory of Pinhole Images", Archive for the History of Exact Sciences, núm. 24 (198I): 267-293.

15. John L. Heilbron, The Sun in the Church: Cathedrals as Solar Observatories (Cambridge, Mass.: Harvard University Press, 1999), 62-8I. 
La primera línea de este tipo parece haber sido construida en 1475 por Toscanelli en Santa Maria di Fiore en Florencia. En la Italia de mediados del siglo XvI, Egnazio Danti construyó una nueva línea meridana en la iglesia Santa Maria Novella (también en Florencia) y en San Petronio en Boloña (seguido por Cassini un siglo más tarde). Estos proyectos se realizaron con fines astronómicos relacionados con la reforma calendárica.

En estos casos, la observación astronómica con cámara oscura estaba anclada a un sitio específico (una iglesia transformada en cámara oscura). En contraste, la cámara oscura se volvió un dispositivo portátil común para la observación y el dibujo en el siglo XviII. Desde mediados de ese siglo, se volvió un equipamiento estándar en expediciones de viajeros europeos a tierras lejanas, y se consideraba como un instrumento para dibujar paisajes exóticos y desconocidos que no podían pasar inadvertidos. Cabe remarcar que a la cámara oscura se le consideró particularmente útil para dibujar paisajes — sobre todo delineaciones de costas y vistas urbanas - y lo fue mucho menos para hacer retratos de habitantes nativos.

Mientras que en el contexto óptico-astronómico el interés principal recaía en entender la propagación de la luz (del sol) por distintas aperturas, antes del siglo XVIII las capacidades creadoras de imágenes de la cámara oscura fueron explotadas en teatros y por escenificadores como Giovanni Battista della Porta. ${ }^{16}$ En el siglo XVIII, en cambio, a la cámara oscura se la asoció con imágenes consideradas veraces y sus usos fueron deslindados de aquellas prácticas teatrales previas dedicadas al entretenimiento e ilusionismo. ${ }^{17}$ Entre 1789 y 1794 la expedición española bajo la dirección de Alessandro Malaspina y José Bustamante viajó por Sudamérica. Su barco traía a bordo una pequeña "cámara óptica" que se usaba para producir vistas de Montevideo y Santiago de Chile (figs. I y 2). A principios del siglo XIX una expedición francesa bajo la dirección de Nicolas Baudin viajó por el Pacífico con una cámara oscura. El dibujante Charles-Alexandre

I6. Para el uso teatral de la cámara oscura y Giovanni Battista della Porta, véase Sergius Kodera, "The Laboratory as Stage: Giovan Battista della Porta’s Experiments", Journal of Early Modern Studies, núm. 3 (20I4): I5-38; William Eamon, "A Theater of Experiments: Giambattista della Porta and the Scientific Culture of Renaissance Naples", en Arianna Borrelli, Giora Hon y Yaakov Zik G., eds., The Optics of Giambattista della Porta (ca. I535-I6I5): A Reassessment. Archimedes, vol. 44 (New Studies in the History and Philosophy of Science and Technology), 2017, https://doi.org/I0.1007/978-3-319-50215-I_2.

17. Joachim Rees, Die verzeichnete Fremde: Formen und Funktionen des Zeichnens im Kontext europäischer Forschungsreisen I770-I830 (Paderborn: Wilhelm Fink, 2015), 284-297; 303-307. 


\section{DOI: https://doi.org/10.22201/iie.18703062e.2021.118.2740}

I8

SVEN DUPRÉ

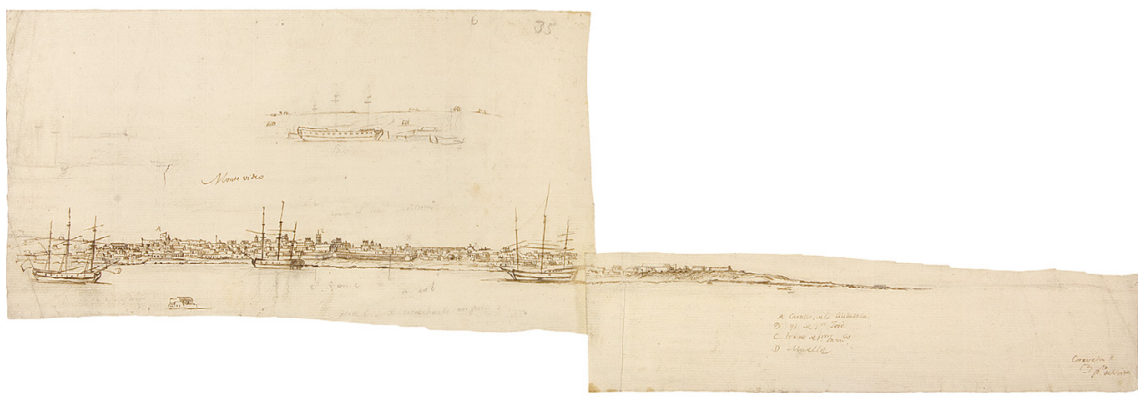

I. Felipe Bauzá, Vista de Montevideo, 1789. Madrid, Museo Naval, Fondo Malaspina, ms. 1724-19.

Lesueur usó el instrumento para recrear vistas de la ciudad de Port Jackson (hoy Sidney), quizá desde una de las tiendas de campaña que se ven al fondo de la vista panorámica de esa población. Otra imagen de Port Jackson muestra un molino holandés proyectando una vista europea —un reclamo territorialsobre un paisaje australiano. El molino denota una forma de visión holandesa que conecta dibujos paisajísticos y mapas con el uso de la cámara oscura, y esa conexión es parte de la cámara oscura como una tecnología visual (fig. 3).

Desde el planteamiento de Crary, la portabilidad transcontinental de la cámara oscura supondría la existencia de un observador pasivo que busca captar la realidad objetiva. Sin embargo, antes de la emergencia del artefacto portátil en el siglo XviII, la cámara oscura no estuvo fija en un sitio específico. ¿Cómo se movía? Voy a sugerir que los textos —y, de hecho, fragmentos de textos, tales como recetas- desempeñaron un papel clave.

\section{Recetas y secretos}

Las recetas son quizá tan antiguas como la escritura. Se conservan, por ejemplo, recetas babilonias de vidrio inscritas en tabletas de arcilla. Los llamados Papiros de Leiden y Estocolmo, que contienen recetas para varias artes y oficios, tuvieron alcance hasta la modernidad temprana. Ya para este periodo, las recetas se habían vuelto objetos ubicuos. ${ }^{18}$ Con frecuencia, las que se leían en

I8. Sobre los Papiros de Leiden y Estocolmo, véase Lawrence Principe, The Secrets of Alchemy (Chicago: University of Chicago Press, 20I3), IO-I3; Sven Dupré, Bert de Munck y Mark Clarke, Transmission of Artists' Knowledge (Bruselas: Royal Flemish Academy of Arts and Sciences, 2012). 


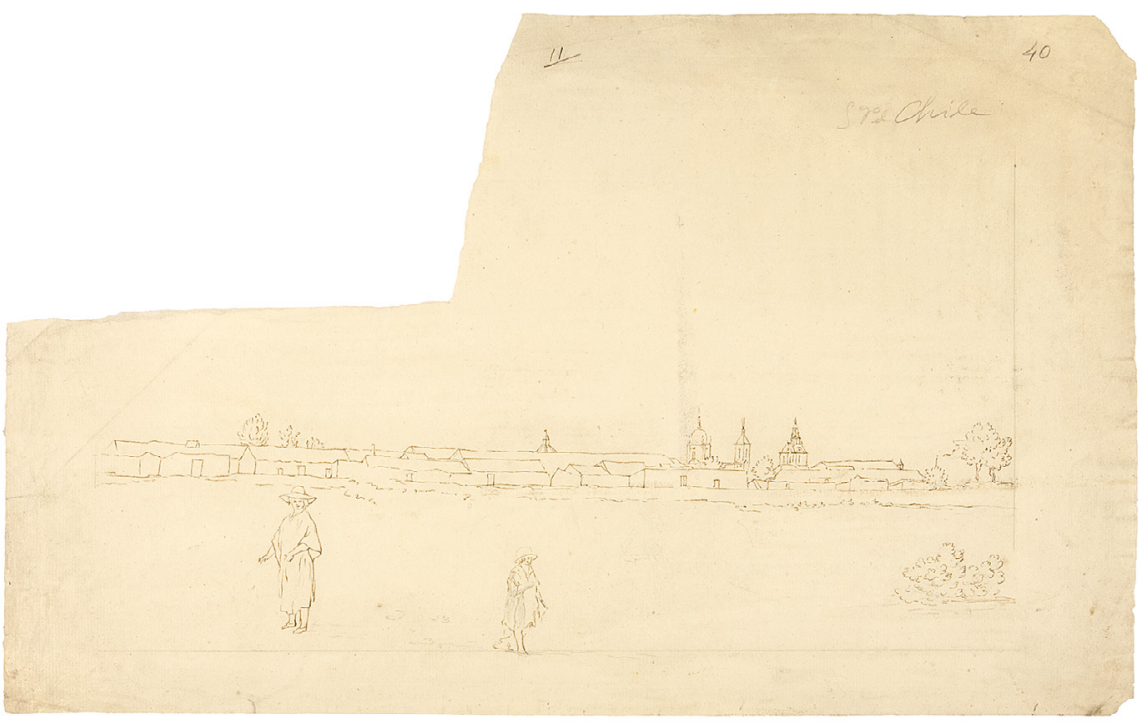

2. Felipe Bauzá, Vista de Santiago de Chile, I790, Museo Naval, Madrid, Fondo Malaspina, carp. 2-I3.

los impresos del siglo Xvi habían pertenecido antes a colecciones manuscritas. El impreso y el manuscrito eran y permanecieron como tradiciones coetáneas. Hay que subrayar aquí el carácter longevo de estas recetas y secretos.

Reunidas con avidez en libros de apuntes manuscritos y promovidas en libros de secretos que inundaban el mercado editorial, estas recetas instruían a los lectores en el colorido del vidrio, la fabricación del oro, y la preparación de remedios. Una buena parte de las recetas que nos han llegado desde finales de la Edad Media y de la modernidad temprana tienen que ver con la medicina y las artes visuales y decorativas. Dentro de esta última categoría, Il libro dell'arte de Cennino Cennini es una de las colecciones mejor conocidas y su fama quizá sólo empata con las recetas y los secretos de taller que compiló Theodore de Mayerne a partir de sus conversaciones con Rubens, Van Dyck, y otros de este estilo. ${ }^{\text {I9 }}$

19. Lara Broecke, Cennino Cennini's Il libro dell'arte: A New English Translation and Commentary with Italian Transcription (Londres: Archetype Publications, 2015). Sobre Mayerne y su manuscrito, véase Hugh Trevor-Roper, Europe's Physician. The Various Life of Sir Theodore de Mayerne (New Haven: Yale University Press, 2006); Ulrike Kern, "The Art of Conservation I: Theodore de Mayerne, the King's Black Paintings and Seventeenth-Century Methods of Restoring and Conserving Paintings", The Burlington Magazine, núm. I57 (2015): 700-708. 


\section{DOI: https://doi.org/10.22201/iie.18703062e.2021.118.2740}

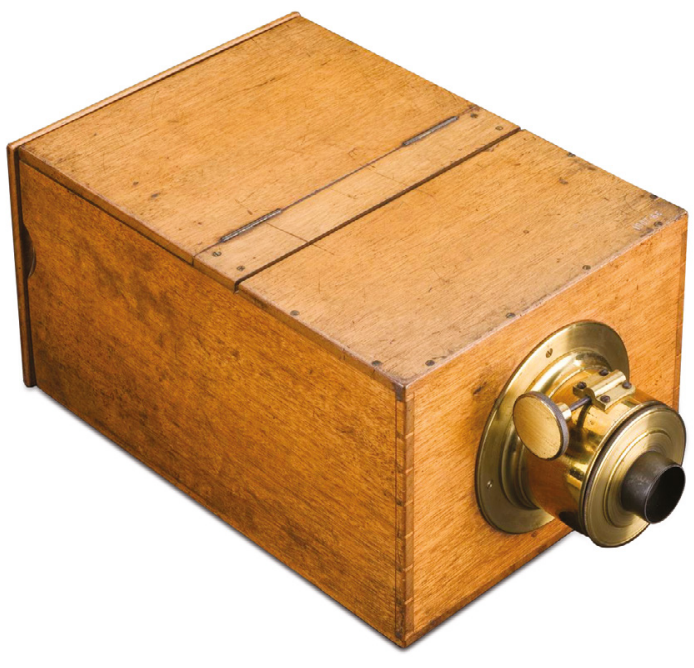

3. Cámara oscura tipo caja, con lente menisco convergente o cóncavo-convexo de $6 \mathrm{~cm}$ y distancia focal de aproximadamente 28 centímetros, ca. 1850. Science Museum Group, imagen consultada el 2I de enero de 202I, en https://collection. sciencemuseumgroup.org.uk/ objects/co3717/camera-obscurabox-type-with-2-3-8-inchmeniscus-optical-drawing-aidcamera-obscura.

No obstante, dichas colecciones son excepciones. Estos ejemplos famosos, asociados al nombre de su autor o compilador, son sólo la punta del iceberg. Bajo la superficie acuosa se esconden cientos de colecciones casi siempre anónimas de (en su conjunto) miles de recetas. Los ejemplos más famosos, como los de Cennini, también son excepcionales porque se enfocan en un solo tema. Un segundo punto que vale la pena establecer es que las colecciones de recetas más típicas eran de naturaleza miscelánea. Las recetas misceláneas también acabaron en las bibliotecas de artistas. Por ejemplo, Christine Sauer ha identificado un manuscrito de este tipo que pasó, en cierto momento, por las manos de Alberto Durero. ${ }^{20}$ Este aspecto encaja en una perspectiva más amplia de la evolución de la lecto-escritura artesana en la modernidad temprana, cuando un número cada vez mayor de artesanos fue capaz de leer y escribir, y tanto la cantidad de libros y de bibliotecas como el número de obras en su posesión también aumentó. ${ }^{21}$ La modernidad temprana fue testigo de una transición en

20. Christine Sauer, "Eine kunsttechnologische Handschrift aus dem Besitz Albrecht Dürers", Dürer-Forschungen (Núremberg: Verlag des Germanischen Nationalmuseums, 2009), II, 275-96.

2I. Michael Hackenberg, "Books in Artisan Homes of Sixteenth-Century Germany", Journal of Library History, núm. 2I (1986): 72-9I; Bert S. Hall, "Der Meister soll auch Kennen, Schreiben und Lesen: Writings about Technology ca. I400-ca. I600 A. D. and their Cultural Implications”, en Early Technologies, Denise Schmandt-Besserat, ed. (Malibú: Undena Publications, 1979), 4758; Pamela O. Long, Openness, Secrecy, Authorship: Technical Arts and the Culture of Knowledge from Antiquity to the Renaissance (Baltimore: Johns Hopkins University Press, 200I). 
la que los artesanos reclamaron su autoría en los conocimientos propios de su oficio y, hasta cierto punto, empezaron a aprender su oficio por medio de textos.

La Magia naturalis de Giovanni Battista della Porta, publicado en 1558 con una versión expandida en 1589 , es uno de los ejemplos más conocidos del género de libros de secretos. En esta obra, entre secretos de todo tipo de saberes productivos, encontramos los secretos ópticos que revelan, por ejemplo, cómo hacer un espejo ustorio o cómo crear una imagen en el aire. En el capítulo io, Della Porta enseña "a ver una imagen que cuelga en el aire" con una lente convexa.

Si colocas la cosa que ha de ser vista detrás de la lente ocular de tal manera que se vea al centro, y si fijas tus ojos en la parte opuesta, verás la imagen entre el vidrio y tus ojos; y si colocas un papel enfrente, lo verás tan claramente que parecerá que una vela encendida arde sobre el papel. ${ }^{22}$

En el capítulo 13 mostró cómo hacer que una imagen aparezca en el aire con un pilar de cristal:

Se mostrará la imagen en el aire, tanto de frente como por detrás. Deja que el objeto esté detrás del pilar, deja que el pilar esté entre éste y el ojo, la imagen aparecerá notablemente colgando en el aire, arriba de la columna, completamente separada de la columna, clara y lúcidamente. ${ }^{23}$

Este último secreto también se encuentra en colecciones de recetas anteriores y contemporáneas al libro de Della Porta. El recetario manuscrito de mediados del siglo Xvi reunido por el boticario Peter van Coudenberghe, por ejemplo, es muy similar en cuanto a contenido y organización a los libros de secretos publicados durante el mismo periodo. ${ }^{24}$ El volumen tiene secciones en latín y

22. "If you put the thing to be seen behind the Lenticular, that it may pass thorow the Centre, and set your eyes in the opposite part, you shall see the Image between the Glass and your eyes; and if you set a paper against it, you shall see it clearly: so that a lighted Candle will seem to burn upon the Paper". Giambattista della Porta, Natural Magick by John Baptista Porta, a Neapolitane: in Twenty Books... Wherein are Set Forth all the Riches and Delights of the Natural Sciences (Londres: Printed for Thomas Young and Samuel Speed, 1658), 368-369.

23. "It will shew the Image in the Air, both before and behind. Let the Object be behind the Pillar, let the Pillar be between that and the eye, the Image will appear outwardly hanging in the Air, above the Pillar, parted everywhere from the Pillar, clearly and perspicuously", Porta, Natural Magick, 370.

24. Sven Dupré, "The Value of Glass and the Translation of Artisanal Knowledge in Early Modern Antwerp”, en Bart Ramakers, Christine Göttler y Joanna Woodall, eds., Trading Values 


\section{DOI: https://doi.org/10.22201/iie.18703062e.2021.118.2740}

holandés. Las recetas en latín son de naturaleza diversa (tratan temas de cocina, medicina, alquimia, y la fabricación de vidrio y colores), mientras que la parte holandesa, más extensa, contiene recetas que son, en su mayoría, de origen artístico-tecnológico: la preparación de colores en diferentes medios, tintas, vidriería y, también en esta sección, secretos ópticos, es decir, recetas para la construcción de espejos. ${ }^{25}$ Las colecciones de recetas eran vehículos para el conocimiento óptico.

El caso de la circulación de copias del Secretum philosophorum es revelador en este sentido. ${ }^{26}$ Originalmente, la obra se compuso en Inglaterra a finales del siglo XIII o inicios del XIV y, aunque estaba dedicada a las siete artes liberales, fue mucho más que un libro de texto universitario. La sección inicial sobre gramática estaba compuesta de recetas que explicaban cómo construir una pluma y cómo preparar tintas. La tercera sección, dedicada a la dialéctica, ofrecía una lista de secretos para engañar a los sentidos, incluyendo algunos para traicionar el sentido de la vista. De una organización más robusta que otros recetarios (conforme al esquema de las artes liberales), esta obra era, no obstante, típicamente miscelánea.

Quisiera hacer varias aseveraciones sobre los libros de secretos a partir del ejemplo del Secretum philosophorum. La primera versa sobre la ambigüedad del sentido. He aquí un secreto para "hacer un espejo en el que muchas imágenes en movimiento aparecerán en un mismo lugar”:

También puedes hacer un espejo en el que, de un sólo vistazo, aparezcan muchas imágenes en movimiento, y así es cómo: toma una caja muy profunda y colócala al fondo un espejo ordinario - es decir, uno cóncavo. Después, toma otros seis o siete espejos convexos del mismo tamaño y, con un cuchillo quítales el plomo, que

in Early Modern Antwerp, Netherlands Yearbook for Art History, 64 (Leiden: Brill, 20I4), I38I6I; E. Vandamme, "Een I6e-eeuws Zuidnederlands receptenboek", Jaarboek van het Koninklijk Museum voor Schone Kunsten (1974): IOI-I37.

25. Por ejemplo, Om brant spiegels te ghieten ("para moldear espejos ustorios"), en Vandamme, "Een i6e-eeuws Zuidnederlands receptenboek", I2I.

26. Robert Goulding, "Deceiving the Senses in the Thirteenth Century: Trickery and Illusion in the Secretum philosophorum", en Magic and the Classical Tradition, Charles Burnett y Will F. Ryan, eds. (Londres: The Warburg Institute, 2006), I35-I62. Véase también Mark Clarke, "Writing Recipes for Non-Specialists, c. I300: The Anglo-Latin 'Secretum philosophorum', Glasgow MS Hunterian IIo”, en Sources and Serendipity: Testimonies of Artists' Practice, Erma Hermens y Joyce H. Townsend, eds. (Londres: Archetype Publications, 2009), 50-64. 
se halla del lado cóncavo. Haz de saber que es muy difícil quitarles todo el plomo adecuadamente, sin romper el vidrio. Así que si quieres limpiar bien los vidrios y remover el plomo, toma un poco de azogue y frota el plomo con él. Inmediatamente se adherirá el plomo y lo penetrará, de tal manera que después de poco tiempo podrás fácilmente remover completamente el plomo del espejo. Ahora, cuando estén muy limpios, colócalos en la caja, pero de tal manera que queden inclinados sobre el espejo y, además, en diferentes posiciones, lo cual harás así. Cuando el primer espejo haya sido colocado al fondo, tomarás el segundo espejo para que un lado quede fijo al primer espejo y el lado opuesto quede a un dedo de él; y de este modo, colocarás los otros espejos en la caja, pero en distintas posiciones. Sobre la superficie de la caja colocarás un espejo (limpiado como se dice arriba) de forma recta y no inclinada y luego los ajustarás tan bien que sólo será posible ver el que quede arriba. Entonces, si ves el espejo, verás tantas imágenes como espejos. Pero si volteas el espejo, verás cómo una imagen siempre se queda en medio y en una posición mientras que las otras imágenes van a su encuentro como si fuera una danza. ${ }^{27}$

El secreto describe dos procesos diferentes: cómo hacer espejos de vidrio (empezando por los espejos convexos, que entonces eran más comunes), y cómo ensamblar los espejos de tal modo que, especificando las distancias y posiciones de los respectivos espejos, se pueda crear un efecto óptico particular (las imágenes danzantes). En contraste con las imágenes "fijas" de la cámara oscura portátil que vendrá después, el movimiento y la animación de las imágenes es clave en estas tecnologías tempranas. Depende de nuestra interpretación de las posiciones y distancias, las formas de armar este instrumento. Aunque es posible reconstruir un objeto óptico siguiendo este texto, como lo hice con Carsten Wirth, la ambigüedad de sentido, que reta la imaginación del lector, es la regla del juego en los libros de secretos (fig. 4). Dicha ambigüedad se incrementa a falta de dibujos que muestren los diseños de los instrumentos. ${ }^{28}$

Otro punto que quiero enfatizar es el de la transmisión. Los secretos no sólo viajaron dentro del Secretum philosophorum sino que también circularon por partes. En este proceso de transmisión, se reorganizaron y reaparecieron en distintos contextos. Veamos el ejemplo de Jean Fusoris, un matemático y

27. Goulding, "Deceiving the Senses in the Thirteenth Century", I35-I62, en especial I55-I56. 28. Sobre (la ausencia) de imágenes en instructivos, véase también Sven Dupré, "Die Sichtbarkeit und Unsichtbarkeit von Körperwissen in der Kodifikation der Künste in der frühen Neuzeit”, Paragrana: Internationale Zeitschrift für Historische Anthropologie 25, núm. I (2016): IIO-I29. 


\section{DOI: https://doi.org/10.22201/iie.18703062e.2021.118.2740}

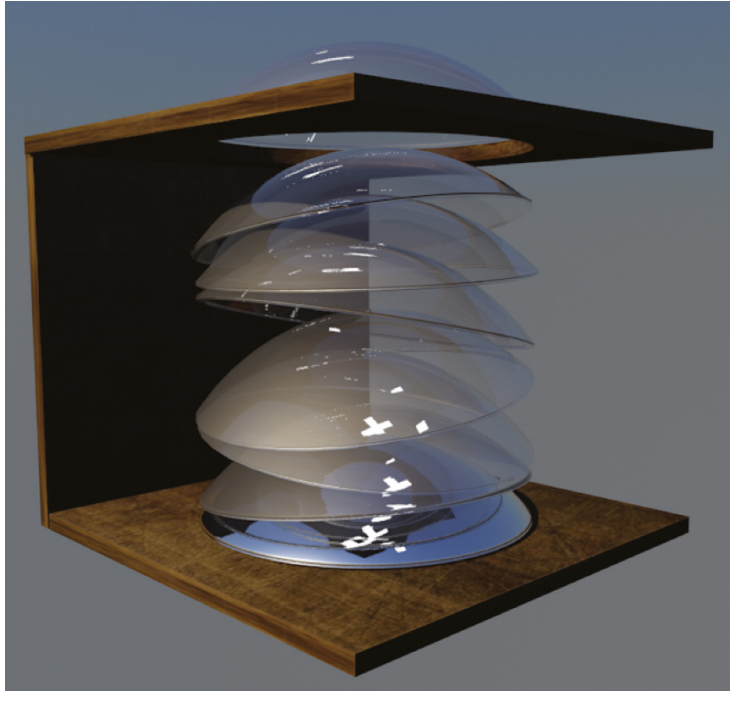

4. Reconstrucción del secreto "Para hacer un espejo en el que muchas imágenes en movimiento aparezcan en un solo lugar", en Sven Dupré, "How-to Optics", Sven Dupré, ed., Perspective as Practice-Renaissance Cultures of Optics (Turnhout: Brepols, 2019), 290.

diseñador de instrumentos de principios del siglo Xv que vivía en París. ${ }^{29}$ Este personaje tenía interés por la óptica y, en particular, por los espejos ustorios. Más ampliamente, como muestran sus anotaciones a la Perspectiva de Witelo, también se interesó por temas de catóptrica y formación de la imagen. Su manuscrito sobre espejos ustorios (una variación del Libellus almakesi compositio) ahora en la Bibliothèque Municipale de Dijon, contiene una nota sobre "speculum in quo visu uno multe apparebunt ymagines se moventes constituere" (cómo hacer un espejo en donde aparezcan muchas imágenes en movimiento de un objeto), tomado del Secretum philosophorum..$^{30}$ En pocas palabras, los secretos ópticos del Secretum philosophorum viajaron como fragmentos o pequeñas partes fuera del texto en el que estaban primero insertos y se combinaron con, por ejemplo, un tratado sobre espejos ustorios.

29. Emmanuel Poulle, Un Constructeur d'instruments astronomiques au XVe siècle: Jean Fusoris (París: Librairie Honoré Champion, 1963).

30. Bibliothèque Municipale, Dijon, 44I (226), fol. 206r. El pasaje completo está transcrito en Grażyna Rosińska, "Optyka w XV wieku: między nauką średniowieczną a nowożytną / Fifteenth-Century Optics: Between Medieval and Modern Science”, Studia Copernicana, núm. 24 (1986): I5I. Un pasaje correspondiente, casi idéntico, en un manuscrito inglés: British Library, Londres, Egerton 2852, fol. igr (transcrito en Rosińska, "Optyka w XV wieku”, I68). 


\section{La manipulación de objetos ópticos}

Un tercer punto: los libros de secretos reunieron y reagruparon los conocimientos ópticos para crear efectos visuales mediante la manipulación de objetos o de instrumentos. En el Secretum philosophorum se trata de espejos (convertidos en esferas de vidrio) y el efecto visual depende de un involucramiento y entrecruzamiento corpóreo con ellos. Los efectos visuales descritos en los secretos sólo suceden cuando la mirada se coloca en un punto determinado respecto de las esferas de vidrio. Este secreto se relaciona con la cámara oscura pero la experiencia del mecanismo óptico difiere de aquella imaginada por Crary. Nuestro énfasis sobre el involucramiento y entrecruzamiento corpóreo se vuelve tanto más nítido en las descripciones de la cámara oscura que pertenecen a la modernidad temprana. Véase, por ejemplo, la descripción que propone el astrónomo Johannes Kepler, cuyo Paralipomena sentó las bases de la teoría de la visión basada sobre la analogía entre el ojo y la cámara oscura. En este libro, Johannes Kepler comentó:

una experiencia [que] vi en Dresde en el teatro de artificio del Elector. [...] Un disco más grueso por en medio o lente cristalina, de un pie de diámetro, estaba a la entrada de un cuarto cerrado frente a una pequeña ventana, que, desviada muy ligeramente hacia la derecha, era la única cosa abierta. Así, cuando la agudeza de la vista atravesaba la oscuridad vacía, también daba fortuitamente contra el sitio de la imagen, que estaba incluso más cerca que la lente. Y ya que la lente estaba mal iluminada, los ojos no eran en gran medida atraídos. Pero las paredes tampoco eran particularmente visibles a través de la lente porque estaban entre mucha

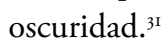

3I. La traductora agradece a Claudio Camacho por su asesoría en la traducción de este pasaje del latín al español. "Cuius experimentum vidi Dresdae in Theatro artificiali Electoris. [...] Discus in medio crassior, seu lens crystallina, pedis diametro, stabat in ingressu camerae clausae contra fenestellam, quae unica patebat, declinantem parum ad dextram. Dum igitur oculorum acies tenebrosam capacitatem pererrant, fortuito, et in locum imaginis incidunt, propiorem quidem quam erat lens. Cum itaque lens malignè illustraretur, oculos non admodum erant conspicui. Sed neque parietes trans lentem admodum erant conspicui; quia in multis tenebris'”, en Johannes Kepler, Gesammelte Werke, Max Caspar y Walter van Dyck, eds., 23 vols., II (Múnich: C. H. Beck, 1938), I64-165 (trad. de Nydia Pineda de Ávila). Para la versión en inglés, véase Johannes Kepler, Optics. Paralipomena to Witelo and Optical Part of Astronomy, William H. Donahue, trad. (Santa Fe: Green Lion Press, 2000), 194. 


\section{DOI: https://doi.org/10.22201/iie.18703062e.2021.118.2740}

El escenario era la Kunstkammer de Dresde, un lugar de exposición en el que se yuxtaponían colecciones de objetos naturales y objetos artificiales, como era típico en las cortes renacentistas. ${ }^{32}$ En una de las salas de la Kunstkammer de Dresde, que había sido convertida en una cámara oscura del tamaño de un cuarto entero, Kepler fue testigo de las imágenes formadas por una lente colocada en la apertura de esta cámara oscura (que, de hecho, era una de las ventanitas de la Kunstkammer que permitía el paso de la luz exterior). En este cuarto oscurecido Kepler observó que "la ventanita y los objetos en torno a ella, que recibían mucha luz, ocultos detrás de la lente, se alzaban en una imagen brillante de ellos mismos en el aire (entre la lente y yo)". ${ }^{33}$

En la experiencia descrita por Kepler, la cámara oscura estaba diseñada como un dispositivo óptico fijo en contraste con el instrumento tipo caja-portátil. La cámara oscura era un cuarto que se preparaba para impedir el paso de la luz y los mecanismos ópticos se instalaban ahí con un propósito específico. En Dresde, una bola de cristal obsequiada al Elector de Sajonia, Augusto I, por el duque de Savoya en 1580, expuesta en el cuarto más importante de la Kunstkammer de Dresde, era ocasionalmente transportada a un cuarto oscurecido dentro de ese mismo recinto para proyectar imágenes. ${ }^{34}$

Lo anterior subraya que la experiencia de la cámara oscura implicaba tanto un proceso como una ocasión. También denota que no había un diseño óptico estándar ni estable para las experiencias del cuarto oscuro. Por el contrario: distintos elementos del diseño (lentes, espejos, aperturas) podían ser reunidos y ensamblados de múltiples maneras para producir diferentes tipos de imágenes. No obstante, ya en el siglo XVII había esfuerzos para que la cámara oscura se volviera un instrumento portátil para dibujar paisajes en el campo. Sin embargo, ejemplos como la picture box desarrollada por Robert Hooke, el encargado de experimentos en la Royal Society de Londres, muestran cuán difícil habrá sido crear un cuarto sin luz a pequeña escala. ${ }^{35}$ Con semejante caja sobre la cabeza, ¿cómo habrá podido el dibujante de Hooke

32. Sven Dupré y Michael Korey, "Inside the Kunstkammer: The Circulation of Optical Knowledge and Instruments at the Dresden Court", Studies in History and Philosophy of Science 40, núm. 4 (2009): 405-420.

33. "At fenestella et circumstantes res, quae multa luce fruebantur, post lentem latentes, claram sistebant in aëre (me inter et lentem) sui imaginem", Kepler, Gesammelte Werke, II, I65 (Kepler, Optics, 194).

34. Dupré y Korey, "Inside the Kunstkammer", 405-420.

35. Sobre la cámara oscura portátil: Joachim Rees, Die verzeichnete Fremde: Formen und 
guardar el equilibrio? (fig. 5). Reconocer los fracasos y los éxitos en la creación de una cámara oscura portátil permite valorar las dificultades prácticas en su uso como instrumento de dibujo. La picture box de Hooke era una extensión del cuerpo del dibujante más que un modelo de visión pasiva y objetiva, como hubiese querido Crary.

En el siglo xvi, la cámara oscura era un instrumento maleable y sus fronteras con otros instrumentos ópticos eran permeables. Por ejemplo, en dicha época, este dispositivo tenía un diseño semejante al telescopio. Desde siglos atrás habían existido testimonios de supuestas prácticas telescópicas. En muchos de estos reportes el instrumento referido era una especie de espejo telescópico (de vista larga). El ejemplo más conocido de la legendaria catóptrica telescópica es quizás el de Faros, el faro de la antigua Alejandría sobre el cual se montó un espejo enorme para otear barcos enemigos a gran distancia (y para incendiarlos). Entre otras historias emblemáticas que circulan, destacan las aseveraciones de los matemáticos del siglo XvI Thomas Digges y William Bourne, quienes dieron información incomparablemente precisa sobre el diseńo óptico de su telescopio. El instrumento se menciona, por primera vez, en I57I cuando Thomas Digges, en la edición de la Pantometría de su padre Leonard Digges, le atribuyó a éste la invención de un telescopio.

Mediante sus continuos esfuerzos tenaces, mi padre, asistido por demostraciones matemáticas, fue hábil y, posicionando espejos [glasses] proporcionales en ángulos convenientemente colocados, muchas veces no sólo descubrió cosas lejanas, leyó letras, contó monedas (con todo y sello e inscripción) que sus amigos le habían tirado a propósito en los campos abiertos de los Downs, sino que también anunció al instante lo que sucedía en lugares privados a siete millas de distancia. ${ }^{36}$

Funktionen des Zeichnens im Kontext europäischer Forschungsreisen 1770-I830 (Paderborn: Wilhelm Fink, 2015), 275-326.

36. "My father by his continual painfull practises, assisted with demonstrations Mathematicall, was able, and sundrie times hath by proportionall Glasses duely situate in convenient angles, not onely discovered things farre off, read letters, numbred peeces of money with the very coyne and superscription thereof, cast by some of his freends of purpose uppon Downes in open fieldes, but also seven myles of declared wat hath beene doon at that instante in private places", Thomas Digges, A Geometrical Practise, Named Pantometria, Divided into Three Bookes, Containing Rules Manifolde for Mensuration of All Lines, Superficies and Solides. With Sundry Straunge Conclusions Both by Instrument and without, and Also by Perspective Glasses, to Set Forth the True Description or Exact Plat of an Whole Region (Londres, 1571), sig. Aiiiv. (trad. del inglés de Nydia Pineda de Ávila). 


\section{the Draught of any Thing. 295}

I $\mathrm{T}$ is, therefore, the Intereft of all fuch, as defire to be rightly and truly informed for the future, to promote the Ufe and Practice of fome fuch Contrivance as I thall now defcribe; whereby any Perfon that can but ufe his Pen, and trace the Profile of what he fees ready drawn for him, fhall be able to give us the true Draught of whatever he fees before him, that continues fo long Time in the fame Pofture, as while he can nimbly run over, with his Pen, the Boundaries, or Out-Lines of the Thing to be reprefented; which

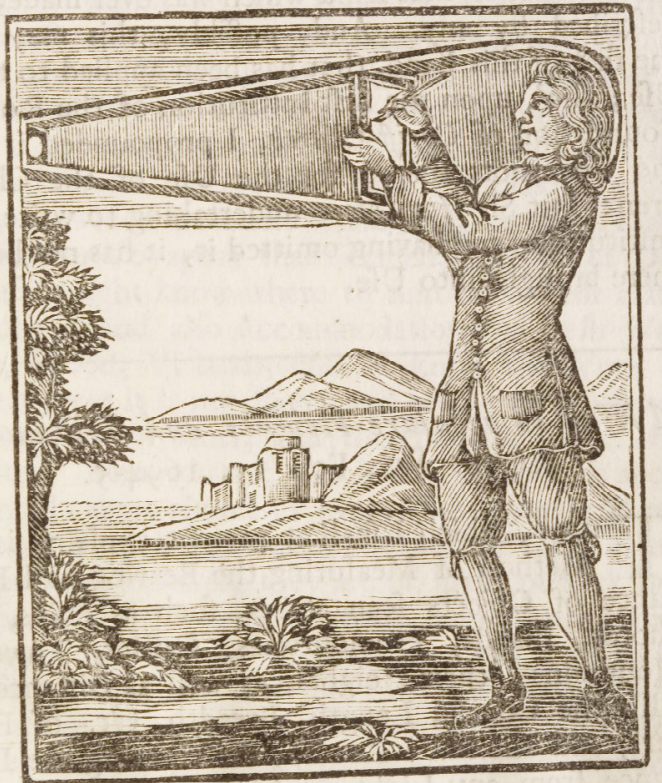

being once truly taken, 'twill not at all be difficult to add the proper Shadows and Light pertinent thereunto. By the fame Inftrument alfo, the Mariner may very eafily and truly draw the Pro$\mathrm{U}_{4}$ fpect

5. Instrumento de dibujo de Robert Hooke, "An Instrument of Use to take the Draught, or Picture of any Thing, Communicated by Dr. Hook (sic) to the Royal Society Dec. 19, I694", tomado de W. Derham, F.R.S., Philosophical Experiments and Observations of the Late Eminent Dr. Robert Hooke S.R.S. and Geom Prof. Grelh and Other Virtuoso's in his Time (Londres: W. and J. Innys, 1727), 295, consultado el 27 de enero de 202I, en https:/echo.mpiwg-berlin. mpg.de/ECHOdocuView?url=/mpiwg/online/permanent/library/RT $3 \mathrm{R}_{12} \mathrm{~V} 8$ / pageimg\&start=24I\&viewMode=images\&mode $=$ imagepath\&pn=3I4. 
A principios de los años noventa del siglo xx, Colin A. Ronan, seguido inmediatamente por Joachim Rienitz y Ewen Whitaker, revivieron el reclamo de que el telescopio había sido inventado en la Inglaterra isabelina. ${ }^{37}$ Sin embargo, ya que ningún vestigio de tal "telescopio isabelino" — tal como fue bautizado el telescopio del siglo xvi por Ronan- ha surgido hasta la fecha, la única evidencia que sirve para esta reivindicación depende de una reconstrucción material del telescopio a partir de la lectura e interpretación de los escritos de Thomas Digges y William Bourne que realizaron Colin, Rienitz y Whitaker. Las reconstrucciones del "telescopio isabelino" contienen una lente convexa y un espejo cóncavo. ${ }^{38}$ Los rayos de luz entran primero por la lente y son reflejados posteriormente por el espejo. Se supone que el observador mira por el espejo dando la espalda a la lente. El espejo debe estar ligeramente inclinado respecto de la lente para evitar que la cabeza del observador bloquee la luz que va de la lente hacia el espejo.

Voy a discutir algunos elementos de esta defensa de la invención del telescopio "isabelino" que de entrada podrían parecer poco relevantes: hay aspectos cruciales de esta reconstrucción material que no se sustentan en el texto. Las discrepancias son relevantes porque subrayan la materialidad móvil de los instrumentos. En la reconstrucción material mencionada, la lente y el espejo se colocan en un tubo. Sin embargo, ninguno de los escritos de Bourne o de Digges justifica esta adición al diseño. De hecho, en los textos no se menciona tubo alguno. Bourne indica que la lente convexa estaba montada dentro de un marco y sujetada firmemente (set fast). ${ }^{39}$ Por otro lado, el espejo convexo no

37. Colin A. Ronan, "The Origins of the Reflecting Telescope", Journal of the British Astronomical Association IOI, núm. I9I (1991), 335-342; Joachim Rienitz, "Make Glasses to See the Moon Large'. An Attempt to Outline the Early History of the Telescope", Bulletin of the Scientific Instrument Society, núm. 37 (1993): 7-9; Ewen A. Whitaker, "The Digges-Bourne Telescope - An Alternative Possibility”, Journal of the British Astronomical Association, núm. IO3 (1993): 310-312.

38. Para una imagen y un análisis de la reconstrucción de Alan Mills, véase Sven Dupré, "William Bourne's Invention. Projecting a Telescope and Optical Speculation in Elizabethan England", en Albert van Helden, Sven Dupré, Rob van Gent y Huib Zuidervaart, eds., The Origins of the Telescope (Ámsterdam: KNAw Press, 2010), I29-I45.

39. "But now to use this glasses, to see a small thing or place that you would view and discerne, set that glasse fast, and the middle of the glasse to stand right with the place assigned, and be sure that it doo not stand oblique or awry by no meanes, and that done, then take a very fayre large looking glasse that is well polished, \& set that glasse directly right with the polished side aginst ye first glasse, to the intent to receive the beame or shadow that commeth thorow 


\section{DOI: https://doi.org/10.22201/iie.18703062e.2021.118.2740}

tendría ese tipo de soporte: es probable que el observador sostuviera el espejo en la mano. Así, cada observador tendría que posicionar el espejo (a una distancia correcta de la lente), inclinándolo y enfocándolo para hallar la imagen telescópica. Esto indica la importancia del involucramiento y el entrecruzamiento corpóreo del observador en su manipulación de las partes móviles del instrumento.

También es notable que los desarrollos de la cámara oscura del siglo XvI hayan llevado al mismo diseño óptico (la combinación de una lente convexa y un espejo cóncavo) que el del telescopio. En su Magia naturalis, Della Porta propuso combinar una lente convexa y un espejo cóncavo dentro de una cámara oscura.

Pero si prefieres que las imágenes aparezcan erectas [con la parte superior hacia arriba], esto será una gran proeza, intentada por muchos, aunque hasta ahora lograda por ninguno [...] Coloca un ojo de vidrio hecho con una lente convexa frente a un hoyo. Desde aquí la imagen cae sobre la lente cóncava. Coloca el espejo cóncavo lejos del centro para que las imágenes que éste recibe invertidas se muestren derechas debido a su distancia del centro. Así, encima del hoyo, sobre el papel blanco verás las imágenes de las cosas, las cuales afuera están tan nítidas y abiertas que nunca cesarás de sentirte encantado y maravillado. Pero para que no hagas esfuerzos en vano tengo que advertirte que la lente tiene que ser puesta en proporción al espejo cóncavo. ${ }^{40}$

the first placed glasse, and set it at such a distance off, that the thing shall marke the beame or shadowe so large, that it may serve your turne", William Bourne, Inventions or Devices. Very Necessary for all Generalles and Captaines, or Leaders of Men, as well by Sea as by Land (Londres: Thomas Woodcock, 1578), 96.

40. "Ut recta omnia videantur. Hoc erit magnum artificium, a multis tentatum, sed non assecutum. Aliqui enim planis speculis foramini oblique obiectis, \& in oppositam tabulam reverberatis, videbant parum recta, sed obscura, $\&$ indiscreta. Nos saepius albam tabulam foramini oblique opponendo, atque e regione foraminis inspicientes, videbamus fere recta, sed pyramis per obliquum dissecta, sine proportione homines, $\&$ in perspicuos ostendebat. Sed tali modo ita fies voti compos. Opponito foramini specillum e convexis fabricatum, inde in speculum concavum imago resiliat. Distet speculum concavum a centro, nam imagines, quas observas recipit, rectas reddit, ob centri distantiam. Sic supra foramen, \& papyrum albam iaculabit imagines rerum obiectarum, tam clare, \& perspicue, ut non satis laetari, non satis mirari possis. Id tamen duximus ad monendum, ne operam frustreris quod proportionati sint oportet circuli specilli, \& concavi portio, quomodo id assequaris, pluries hic declarabitur. Docebimus etiam quomodo fieri possit”, en Giambattista della Porta, Magia naturalis (Nápoles: Salvianum, 
Esto refuerza los aspectos de las recetas y los libros de secretos que he querido establecer, sobre todo en lo que concierne a la ambigüedad del sentido. Claramente, la instrucción de que la lente y el espejo sean puestos en proporción reta la imaginación del lector para que funcione el experimento.

\section{Conclusión}

Quisiera concluir enfatizando la importancia de las recetas y los secretos en la movilización de las tecnologías visuales. Los secretos reempaquetaron - reunieron y revistieron - los conocimientos ópticos a modo de recortes de instructivos. El énfasis de los secretos estaba puesto justamente en la manipulación de los objetos y de los instrumentos para la creación de efectos visuales. En contraste con el régimen escópico geométrico de Crary, que hace del dibujante un observador pasivo, estos instrumentos de visión (la cámara oscura era tan sólo uno entre un grupo maleable de ellos), dependían del involucramiento y entrecruzamiento corpóreo del observador y de la manipulación de las partes móviles de los instrumentos para crear efectos ópticos. Al reempaquetar el conocimiento óptico como recetas y secretos, éste pudo viajar más fácilmente y alcanzar un público que, hasta el siglo Xvi, nunca había sido tan amplio. La estructura de los libros de secretos también incitó a los lectores a probar y experimentar las recetas ópticas, y así lo hicieron: la experiencia del observador estaba inmersa en los mundos del hacer y el actuar. Al reimaginar los efectos visuales y recrear los instrumentos, los lectores dieron movilidad a las tecnologías ópticas antes, incluso, de que los viajeros transportaran la caja portátil de la cámara oscura a lo largo del globo. En nuestro mundo saturado de imágenes quizás perdamos de vista que los textos y la imaginación fueron cruciales para que incluso las tecnologías visuales se movieran. \$

1589), lib. 17, cap. 66; véase Michael John Gorman, "Art, Optics and History. New Light on the Hockney Thesis", Leonardo, núm. 36 (2003): 295-30I.

N.B. Esta investigación recibió financiamiento del European Research Council (ERC) bajo el programa de investigación e innovación European Union's Horizon 2020 (convenio No 648718). 